\title{
Biomass equations for four shrub species in subtropical China
}

\author{
Hui-Qing Zeng · Qi-Jing Liu · Zong-Wei Feng • \\ Ze-Qing Ma
}

Received: 12 March 2008/ Accepted: 9 August 2009/Published online: 3 October 2009

(C) The Japanese Forest Society and Springer 2009

\begin{abstract}
Estimation of shrub biomass can provide more accurate estimates of forest biomass and carbon sequestration. We developed species-specific biomass regression models for four common shrub species, Chinese loropetal (Loropetalum chinense), white oak (Quercus fabri), chastetree (Vitex negundo var. cannabifolia), and Gardenia (Gardenia jasminoides), in southeast China. The objective of this study was to derive appropriate regression equations for estimation of shrub biomass. The results showed that the power model and the quadratic model are the most appropriate forms of equation. $C A$ (canopy area, $\mathrm{m}^{2}$ ) as the sole independent variable was a good predictor of leaf biomass. $D^{2} H$, where $D$ is the basal diameter $(\mathrm{cm})$ and $H$ is the shrub height $(\mathrm{cm})$, is a good predictor of branch and root biomass, except for $V$. negundo var. cannabifolia and the root biomass of $L$. chinense. For total biomass, $D^{2}$ is the
\end{abstract}

H.-Q. Zeng

Environmental and Chemical Engineering College of Nanchang University, 330031 Jiangxi, China

H.-Q. Zeng · Z.-W. Feng

State Key Laboratory of Urban and Regional Ecology,

Research Center for Eco-Environmental Sciences,

CAS, 100085 Beijing, China

H.-Q. Zeng

Graduate University of the Chinese Academy of Sciences, 100039 Beijing, China

Q.-J. Liu ( $\bowtie)$

Department of Forest Sciences, Beijing Forestry University,

100083 Beijing, China

e-mail: liuqijing@gmail.com

Z.-Q. Ma

Institute of Geographical Sciences and Natural Resources

Research, CAS, 100101 Beijing, China best variable for estimation of $L$. chinense and G. jasminoides, and $D^{2} H$ is the best variable for estimation of $Q$. fabri and $V$. negundo var. cannabifolia. Although variables $D^{2}, D^{2} H$, and $H$ are the preferred predictors for biomass estimation, $C V$ (canopy projected volume, $\mathrm{m}^{3}$ ) could be used alone to predict branch, root, and total biomass in shrub species with acceptable accuracy and precision.

Keywords Biomass - Regression equation - Shrub

\section{Introduction}

Vegetation biomass is an important ecosystem attribute. The biomass of herbs, shrubs, and trees is vital for herbivores and their subsequent predators and for ecosystem management. For individual trees or forest stands, information on biomass is essential for understanding the changes in energy, carbon, and nutrient flows resulting from changes in forest land use (Houghton 1991; VEMAP Members 1995; Brown 1997; Marland et al. 1997; Schimel et al. 2000). Shrub biomass is an important component of the total forest biomass, especially in natural stands. However, compared with arboreal biomass, shrub biomass is often neglected in biomass research because of the lack of methodology and difficulty in calculation. Some research has gone into estimating the biomass of individual shrub species (Murray and Jacobson 1982; Frandsen 1983; Návar et al. 2002; Paton et al. 2002; Návar et al. 2004). However, shrub biomass equations for the subtropical ecosystem in China have been little studied.

Total harvesting is generally impractical or inappropriate in shrub studies, so allometric methods have been developed for estimation of total biomass from nondestructive surrogate measurements such as shrub height and 
diameter at breast/basal level (Smith and Brand 1983; Vora 1988; Buech and Rugg 1989; Tietema 1993). Equations used to estimate plant organ biomass and total biomass are required for better understanding of the carrying capacity of plant communities for several purposes, for example grazing, timber, fuel wood, other non-timber forest products, and the environmental services provided by sequestering $\mathrm{CO}_{2}$. Developing accurate allometric equations for shrub biomass estimation in southeast China is essential for at least two reasons. First, the accelerating "woody thickening"-grasslands are becoming woodlands and woodlands are becoming thicker-has heightened its importance. Second, measurement of carbon flux has local importance in study of the $\mathrm{CO}_{2}$ cycle. Study of forest biomass is very important for constructing the coupling relationship between community processes and flux observations and for validating and calibrating flux observations. Estimation of shrub biomass can help to produce more accurate estimates of forest biomass.

Our primary objective was to establish dimensional relationships between three properties, $D$ (basal diameter, $\mathrm{cm}$ ), $H$ (height, $\mathrm{cm}$ ), and $C$ (crown width, $\mathrm{cm}$ ), and organ/ total biomass $(\mathrm{g})$ for the four dominant understory shrubs. A secondary objective was to develop allometric equations with $H$ and $C$ as variables for the four species in the investigation of forest communities.

The allometric regression equations developed in this paper are only valid within the range of $D, H$ and $C$ covered by our sampling program. We therefore recommend that you obtain tree and shrub measurements of $D, H, C$, etc., before applying these equations. It is also possible that the allometric relationships depend on stand structure and their fit to plants in a particular stand should be checked.

\section{Materials and methods}

\section{Site description}

Data were collected from sample plots in Qianyanzhou Ecological Station of the Chinese Academy of Science (QYZ station; $26^{\circ} 44^{\prime} 52^{\prime \prime} \mathrm{N}, 115^{\circ} 03^{\prime} 47^{\prime \prime} \mathrm{E}$ ). The elevation of QYZ station is about $102 \mathrm{~m}$. The subtropical monsoon climate is characterized by a warm winter and a hot summer, abundant but unevenly distributed rainfall, and high humidity. The annual precipitation is $1,487 \mathrm{~mm}$, and the average temperature is $18.0^{\circ}$ (1985-2004). Rainfall is heaviest in late spring and early summer with about 45-50\% falling between March and June. The substratum is dominated by a red soil, $100 \mathrm{~cm}$ in depth. In addition, there are small proportions of paddy soil, fluvo-aquic soil, meadow soil, etc. The parent materials are red sandstone, glutenite, mudstone, and river alluvium.
In the stand studied the trees are around 20 years old. Slash pine (Pinus elliottii Engelm.) and masson pine (Pinus massoniana Lamb.) are dominant, followed by Chinese fir (Cunninghamia lanceolata (Lamb.) Hook.). The height of the canopy layer is $15 \mathrm{~m}$. According to an investigation in 2004, the average DBH (diameter at breast height), height, and density of the slash pine forest were $18.3 \mathrm{~cm}, 14.5 \mathrm{~m}$, and 1,650 trees/ha, respectively. The average density of the shrub layer was about 400 shrubs/ha. The shrub layer is dominated by Chinese loropetal (Loropetalum chinense (R. Br.) Oliv.), white oak (Quercus fabri Hance), and chastetree (Vitex negundo var. cannabifolia (Sieb. et Zucc.) Hand.-Mazz.). The height of the shrub layer is less than $4 \mathrm{~m}$.

\section{Materials}

Four shrub species were selected for conducting this research: Chinese loropetal (Loropetalum chinense), white oak (Quercus fabri), chastetree (Vitex negundo var. cannabifolia), and Gardenia (Gardenia jasminoides). These species are distributed widely in subtropical China and they belong to the most common floristic groups.

For each species, 21-24 individuals that covered the whole range of size of the studied species were selected for investigation. The maximum basal diameter $\left(D_{1}\right)$, minimum basal diameter $\left(D_{2}\right)$, height $(H)$, maximum crown width $\left(C_{1}\right)$, and minimum crown width $\left(C_{2}\right)$ were measured before harvesting. The average values, $D=$ $\left(D_{1}+D_{2}\right) / 2, C=\left(C_{1}+C_{2}\right) / 2$, were adopted for establishing equations. With these variables, plant canopy area $\left(C A, \mathrm{~m}^{2}\right)$ and plant canopy projected volume $\left(C V, \mathrm{~m}^{3}\right)$ were calculated as: $C A=\pi C^{2} / 4, C V=C A \times H$. For each individual, leaves, branches (including stem and stalk of shrubs), and roots were weighed separately after harvesting. The dry weight of each component was measured after the samples had been kept in a drying oven at $80^{\circ}$ for $24 \mathrm{~h}$. Total biomass included branch biomass, leaf biomass, and root biomass. Average values, maximum values, minimum values, and standard deviations of $D, H, C, D^{2}, D^{2} H, C A, C V$, branch biomass, leaf biomass, root biomass, and total biomass are listed in Table 1.

\section{Modeling}

Regression analysis was conducted for the purpose of establishing the relationship between organ/total biomass and $D, H, C A$ and various combinations of $D$ and $H$. By comparing regression coefficients among various forms of equations, the following equations were selected for describing the characteristics of organ and total biomass of each species. 
Power model : $y=a x^{b}$

Quadratic model : $y=a+b x+c x^{2}$

The total variance for additive equations is conventionally determined by the summation of squared residuals. SPSS (11.0) was used for regression analysis. The coefficient of determination $\left(R^{2}\right)$, the standard error of the estimate (SEE) and the $F$ value were used for evaluation of the goodness of fit and for comparisons of alternative biomass models. The equations were originally described in previous reports ( $\mathrm{Lu}$ and Lai 2003):

$$
\begin{aligned}
& R^{2}=1-(\operatorname{RSS} / \mathrm{TSS}), \quad \operatorname{RSS}=\sum_{i=1}^{n}\left(y_{i}-\hat{y}_{i}\right)^{2}, \\
& \mathrm{TSS}=\sum_{i=1}^{n}\left(y_{i}-\bar{y}\right)^{2}, \\
& \bar{y}=\left[\sum_{i=1}^{n} y_{i}\right] / n \\
& F=\frac{(\mathrm{TSS}-\mathrm{RSS}) / 1}{\operatorname{RSS} /(n-2)}
\end{aligned}
$$

where $n$ is the number of observations, $\hat{y}_{i}$ is the estimated biomass $(\mathrm{g}), y_{i}$ is the observed biomass $(\mathrm{g})$, and $\bar{y}$ is the mean of observed value of $y_{i}$.

\section{Results}

The best-fit equations for estimated organ and total biomass are shown in Table 2. These species-specific regression equations were statistically significant $(p<0.001)$. The $R^{2}$ value varied from a low of 0.756 for root biomass of $L$. chinense to a high of 0.997 for branch biomass of G. jasminoides.

Because of the variation in morphological features, the best-fit equations for both organ and total biomass differed among populations. For $Q$. fabri, V. negundo var. cannabifolia, and $G$. jasminoides, the quadratic equations showed the highest $R^{2}$-value for total biomass and organ biomass except for the foliar biomass of $V$. negundo var. cannabifolia. For L. chinense, power models with $D^{2}, C A$ and $H$ as independent variables showed the best fit for biomass of branches, leaves, and roots, respectively (Table 2).

Equations with $C A$ as the sole independent variable had the highest $R^{2}$ for leaf biomass of all species. In comparison, equations with $D^{2} H$ as the sole independent variable gave the highest $R^{2}$ for branch and root biomass except for branch biomass of $V$. negundo var. cannabifolia and root biomass of L. chinense. For total biomass, equations with $D^{2}$ showed the highest $R^{2}$ for L. chinense and G. jasminoides, and equations 
Table 2 Best fitted allometric equations for four shrub species

\begin{tabular}{|c|c|c|c|c|c|c|c|c|c|}
\hline Species & Organ & Variable & Equation & $a$ & $b$ & $c$ & $R^{2}$ & SEE & $F$ value \\
\hline \multirow[t]{4}{*}{ L. chinense } & Branch & $\mathrm{x}=D^{2} H$ & $y=a x^{\mathrm{b}}$ & 0.450 & 0.930 & - & 0.971 & 0.34 & $742.61 * * *$ \\
\hline & Leaves & $x=C A$ & $y=a x^{\mathrm{b}}$ & 25.294 & 1.076 & - & 0.901 & 0.61 & $200.34 * * *$ \\
\hline & Root & $x=H$ & $y=a x^{\mathrm{b}}$ & 0.007 & 1.704 & - & 0.756 & 0.75 & $68.11 * * *$ \\
\hline & Total & $x=D^{2}$ & $y=a+b x+c x^{2}$ & 7.558 & 63.666 & $2.280 \mathrm{E}+01$ & 0.975 & 31.12 & $408.75 * * *$ \\
\hline \multirow[t]{4}{*}{ Q. fabri } & Branch & $x=D^{2} H$ & $y=a+b x+c x^{2}$ & 5.800 & 0.225 & $5.840 \mathrm{E}-04$ & 0.978 & 34.84 & $395.18 * * *$ \\
\hline & Leaves & $x=C A$ & $y=a+b x+c x^{2}$ & 2.622 & 32.468 & $1.803 \mathrm{E}+01$ & 0.905 & 16.68 & $86.03 * * *$ \\
\hline & Root & $x=D^{2} H$ & $y=a+\mathrm{bx}+c x^{2}$ & -69.469 & 1.168 & $4.000 \mathrm{E}-04$ & 0.975 & 211.05 & $352.55 * * *$ \\
\hline & Total & $x=D^{2} H$ & $y=a+b x+c x^{2}$ & -55.975 & 1.417 & $1.000 \mathrm{E}-03$ & 0.983 & 207.77 & $534.23 * * *$ \\
\hline \multirow[t]{4}{*}{ V. negundo var. cannabifolai } & Branch & $x=H$ & $y=a+b x+c x^{2}$ & 4.339 & -0.164 & $2.000 \mathrm{E}-03$ & 0.936 & 2.65 & $153.41 * * *$ \\
\hline & Leaves & $x=C A$ & $y=a x^{\mathrm{b}}$ & 6.864 & 0.808 & - & 0.765 & 0.54 & $71.62 * * *$ \\
\hline & Root & $\mathrm{x}=D^{2} H$ & $y=a+b x+c x^{2}$ & 1.823 & 0.141 & $3.000 \mathrm{E}-04$ & 0.974 & 6.91 & $398.94 * * *$ \\
\hline & Total & $x=D^{2} H$ & $y=a+b x+c x^{2}$ & 2.342 & 0.422 & $-6.070 \mathrm{E}-05$ & 0.968 & 8.80 & $317.09 * * *$ \\
\hline \multirow[t]{4}{*}{ G. jasminoides } & Branch & $x=D^{2} H$ & $y=a+b x+\mathrm{cx}^{2}$ & 1.376 & 0.134 & $1.000 \mathrm{E}-04$ & 0.997 & 4.66 & $3609.80 * * *$ \\
\hline & Leaves & $x=C A$ & $y=a+b x+c x^{2}$ & 0.536 & 20.087 & $3.540 \mathrm{E}-01$ & 0.789 & 4.43 & $37.33 * * *$ \\
\hline & Root & $x=D^{2} H$ & $y=a+b x+c x^{2}$ & 1.951 & 0.006 & $8.340 \mathrm{E}-05$ & 0.995 & 2.25 & $2183.61 * * *$ \\
\hline & Total & $x=D^{2}$ & $y=a+b x+c x^{2}$ & 4.753 & -5.909 & $2.629 \mathrm{E}+01$ & 0.997 & 7.22 & $3216.50 * * *$ \\
\hline
\end{tabular}

$D$ basal diameter, $H$ height, $C A$ canopy area $\left(C A=\pi C^{2} / 4\right.$, where $C$ is crown width)

$* * * p<0.001$

Table 3 Allometric regressions of biomass with $C V$ for shrubs

\begin{tabular}{|c|c|c|c|c|c|c|c|c|c|}
\hline Species & Organ & Variable & Equation & $a$ & $b$ & $c$ & $R^{2}$ & SEE & $F$ value \\
\hline \multirow[t]{4}{*}{ L. chinense } & Branch & $x=C V$ & $y=a x^{\mathrm{b}}$ & 76.9140 & 0.8075 & - & 0.893 & 0.66 & $183.18 * * *$ \\
\hline & Leaves & $x=C V$ & $y=a x^{\mathrm{b}}$ & 13.6629 & 0.7716 & - & 0.893 & 0.63 & $182.81 * * *$ \\
\hline & Root & $x=C V$ & $y=a x^{\mathrm{b}}$ & 48.4808 & 0.4860 & - & 0.571 & 1.00 & $29.23 * * *$ \\
\hline & Total & $x=C V$ & $y=a+b \mathrm{x}+\mathrm{cx}^{2}$ & 23.2917 & 127.8694 & -6.0428 & 0.875 & 69.64 & $73.21 * * *$ \\
\hline \multirow[t]{4}{*}{ Q. fabri } & Branch & $x=C V$ & $y=a+b \mathrm{x}+\mathrm{cx}^{2}$ & 13.4830 & 90.2780 & 3.0837 & 0.976 & 36.17 & $366.01 * * *$ \\
\hline & Leaves & $x=C V$ & $y=a+b \mathrm{x}+\mathrm{cx}^{2}$ & 4.0915 & 19.7866 & 0.7333 & 0.904 & 16.83 & $84.29 * * *$ \\
\hline & Root & $x=C V$ & $y=a+b \mathrm{x}+\mathrm{cx}^{2}$ & 9.2658 & 406.9591 & 28.8700 & 0.928 & 358.66 & $116.19 * * *$ \\
\hline & Total & $x=C V$ & $y=a+b \mathrm{x}+\mathrm{cx}^{2}$ & 26.8425 & 517.0213 & 32.6874 & 0.947 & 372.43 & $160.07 * * *$ \\
\hline \multirow[t]{4}{*}{ V. negundo var. cannabifolai } & Branch & $x=C V$ & $y=a+b \mathrm{x}+\mathrm{cx}^{2}$ & 2.8619 & 78.0886 & -50.5326 & 0.774 & 4.97 & $35.96 * * *$ \\
\hline & Leaves & $\mathrm{x}=C V$ & $y=a x^{\mathrm{b}}$ & 4.5312 & 0.6186 & - & 0.768 & 0.54 & $72.68 * * *$ \\
\hline & Root & $x=C V$ & $y=a x^{\mathrm{b}}$ & 37.8840 & 0.5810 & - & 0.593 & 0.76 & $32.10 * * *$ \\
\hline & Total & $x=C V$ & $y=a x^{\mathrm{b}}$ & 91.3383 & 0.6012 & - & 0.759 & 0.54 & $69.38 * * *$ \\
\hline \multirow[t]{4}{*}{ G. jasminoides } & Branch & $x=C V$ & $y=a+b \mathrm{x}+\mathrm{cx}^{2}$ & 0.9223 & 67.3647 & 3.1488 & 1.000 & 1.56 & $32361.15 * * *$ \\
\hline & Leaves & $x=C V$ & $y=a+b \mathrm{x}+\mathrm{cx}^{2}$ & 2.0093 & 8.5411 & -0.2791 & 0.691 & 5.23 & $22.40 * * *$ \\
\hline & Root & $x=C V$ & $y=a+b \mathrm{x}+\mathrm{cx}^{2}$ & 1.3090 & 12.1151 & 3.9570 & 0.999 & 1.01 & $10868.61 * * *$ \\
\hline & Total & $x=C V$ & $y=a+b \mathrm{x}+\mathrm{cx}^{2}$ & 4.2425 & 87.8648 & 6.8594 & 0.999 & 4.64 & $7816.08 * * *$ \\
\hline
\end{tabular}

$C V$ canopy projected volume $\left[C V=C A \times H\right.$, where $C A$ is canopy area $\left(C A=\pi C^{2} / 4\right), H$ is height, and $C$ is crown width]

$* * * p<0.001$

with $D^{2} H$ fit best for $Q$. fabri and $V$. negundo var. cannabifolia (Table 2).

Species-specific allometric equations with projected volume only were developed for organs and total biomass (Table 3). They showed a close relationship between $C V$ and organ/total biomass $\left(R^{2}>0.691\right)$ except for the root biomass of L. chinense $\left(R^{2}=0.571\right)$ and $V$. negundo var. cannabifolia $\left(R^{2}=0.593\right)$. Compared with the variables in Table 2, $C V$ also resulted in very good correlation for biomass estimation, e.g. branch biomass of $Q$. fabric $\left(R^{2}=0.976\right)$, total biomass of $Q$. fabri $\left(R^{2}=0.947\right)$, branch biomass of $G$. jasminoides $\left(R^{2}=1.000\right)$, root biomass of $G$. jasminoides $\left(R^{2}=0.999\right)$, and total biomass of G. jasminoides $\left(R^{2}=0.999\right)$. Furthermore, the $R^{2}$-value of 
the regression model with $C V$ (Table 3) was higher than that with other properties (Table 2) as the independent variables in estimation of branch, root, and total biomass of G. jasminoides.

\section{Discussion}

Regression equations for estimating total and organs biomass

Allometric equations with easy-to-sample variables are commonly used for forest inventories and ecological studies (Satoo and Madgewick 1982; Araújo et al. 1999; Montès et al. 2000). Our study showed that the quadratic model and power model were most reliable for estimating organ and total biomass of the four shrub species. A quadratic equation is a common model used to estimate shrub biomass (Sah et al. 2004; Foroughbakhch et al. 2005), and our results are consistent with previous reports that the biomass of shrub populations can be well described with architectural variables (Foroughbakhch et al. 2005). The quadratic model with $D^{2}$ was the best predictor of total biomass of $L$. chinense and G. jasminoides. In comparison, the quadratic model with $D^{2} H$ had the highest $R^{2}$ for $Q$. fabri and $V$. negundo var. cannabifolia. For $L$. chinense, power models with $D^{2}, C A$, and $H$ as the independent variables provided the best fits for branch, leaf, and root biomass, respectively.

Usually, a power model with $(D B H)^{2} H$ as the predictor variable is regarded as the best theoretical equation for shrub biomass estimation. Some previous studies suggested that stem diameter is the best predictor for biomass estimation (Haase and Haase 1995; Paton et al. 1998). In our study of the four species, the basal diameter was measured instead of stem diameter, because of the morphology of shrub species. Our result showed that only the branch biomass estimate model of $L$. chinense conformed to the theoretical equation. For estimation of total biomass of $Q$. fabri and $V$. negundo var. cannabifolia, the quadratic model with $D^{2} H$ was better than the power model with $D^{2} H$ (Table 2). Because of the morphology of shrub species, such as multiple stems and ramification at low height, an empirical equation was better than the theoretical equation in our research.

\section{Regression parameter analysis}

For establishing regressions of shrub biomass, $D, D^{2} H, C A$, and $H$ are typically used as independent variables (Murray and Jacobson 1982; Vora 1988; Paton et al. 2002; Návar et al. 2004). In some cases, $D$ is the best predictor (Clough and Scott 1989; Haase and Haase 1995; Paton et al. 1998,
2002). However, we found that $D^{2}$ or $D^{2} H$ were better than $D$. For estimation of total biomass, in particular, the best-fit regression models were those with $D^{2}$ or $D^{2} H$ as the sole variable. This is consistent with previous studies that $D^{2}$ and $D^{2} \mathrm{H}$ are suitable variables for estimation of the biomass of small trees of hardwood species (Williams and McCleanahen 1984).

Although the inclusion of height in biomass regression is less common for shrubs (Peek 1970; Murray and Jacobson 1982; Halpern et al. 1996) than for trees, this study revealed that inclusion of $H$, or $D^{2} H$, in the models improved the precision in branch and total biomass estimation, e.g. $Q$. fabri. In addition, $H$ was the best variable in equations for root biomass of $L$. chinense and branch biomass of $V$. negundo var. cannabifolia.

$C A$ alone has been used in some studies to estimate biomass (Martin et al. 1981; Ohmann et al. 1981; Halpern et al. 1996). For all the species in our study, $C A$ as the independent variable did in fact raise precision of foliar biomass estimation (Table 2), and we found a good relationship between $C A$ and leaf biomass $\left(R^{2}>0.765\right)$. This suggests that $C A$ is the best descriptor for estimation of foliar biomass. $C A$ as the single independent variable in biomass regression has also been recognized by others (Paton et al. 1998, 2002; Sah et al. 2004). A previous study indicated that leaf biomass depends on stand factors (Satoo and Madgewick 1982). Thus our result was because there are free spaces for shrubs to develop their canopy in the understory of the pine forest and their branches tend to grow towards the horizontal periphery, forming an extended crown. Although regressions with $C A$ can provide good fits for leaf biomass estimation, it is not the best variable for estimation of branch, root and total biomass.

\section{Regression model analysis with $C V$ as a sole variable}

In practice, the stem diameter can be obtained easily in a single-stem plant, but it was difficult to obtain an accurate stem diameter for a multi-stem plant. Consequently the basal diameter was used instead of stem diameter. However, it is inconvenient to measure the basal diameter of a plant because there is always thick litter fall or ground cover in a shrub community. Comparatively, measuring $H$ and $C$ of shrub species were more convenient, quicker, and less laborious than measuring the basal diameter. Especially for those shrub species with numerous stem, $H$ and $C$ could be used instead of stem basal diameter (Brown 1976). Consequently $C$ and $H$ of shrubs are recorded in the investigation of forest communities. Moreover, many reports have shown that $C V$ is sometimes the best variable for estimation of biomass (Paton et al. 2002; Foroughbakhch et al. 2005). In this study, species-specific allometric equations showed a close relationship between 

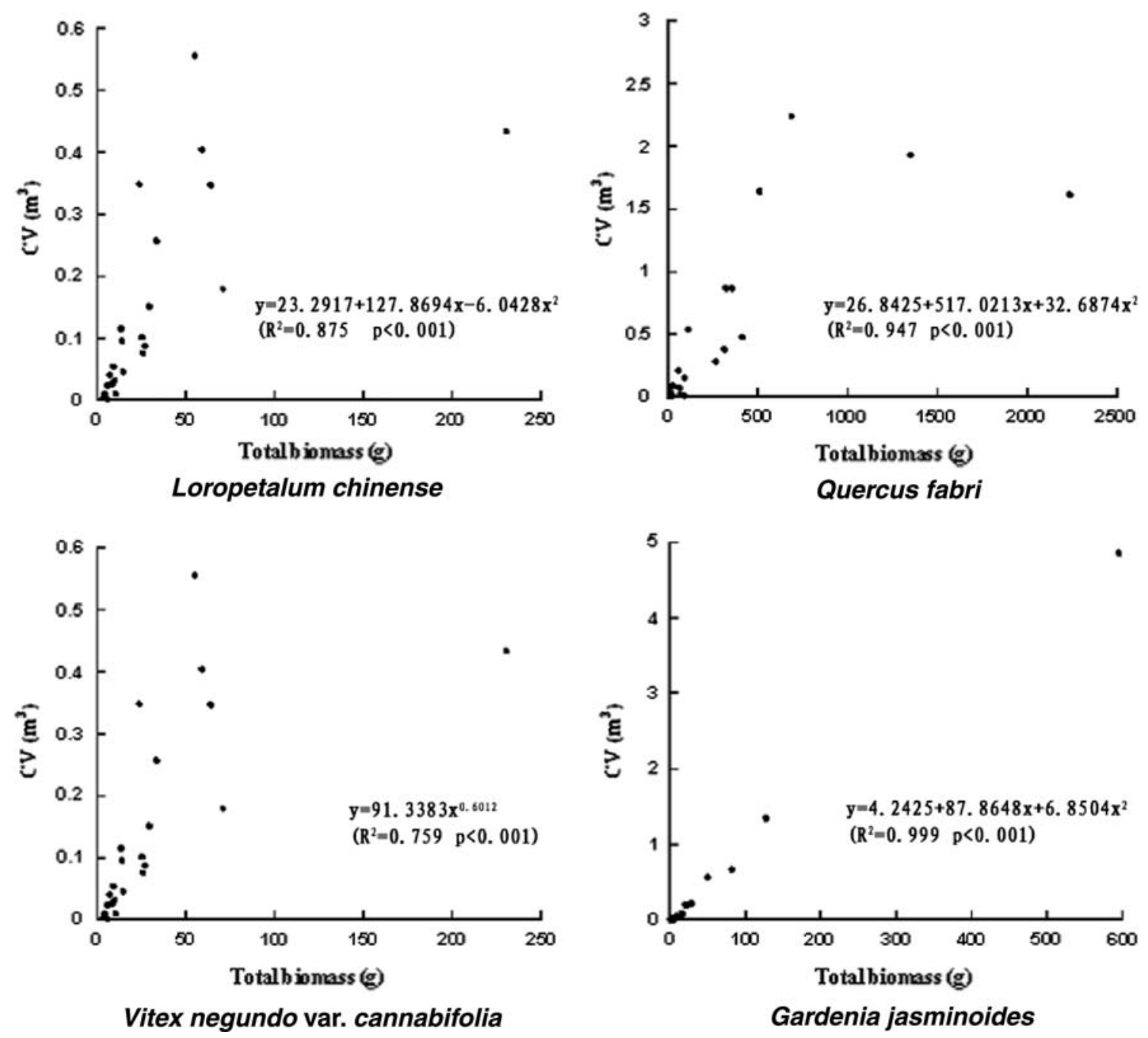

Fig. 1 Scatter maps between total biomass $(\mathrm{g})$ and $C V\left(\mathrm{~m}^{3}\right)$ of the four shrub species

$C V$ and organ and total biomass (Table 3). The scatter maps (Fig. 1) showed that a quadratic model could express the relationship between total biomass and $C V$ of $L$. chinense, Q. fabri, and G. jasminoides. For $V$. negundo var. cannabifolia, however, a power model is preferable to express that relationship.

Although regression models with $C A$ as a single variable were the best-fit equations for foliar estimation for the four species, models with the integrated $C V$ variable that combines $C A$ and $H$ were developed for the shrubs. This was found to be reasonable because $C A$-only models effectively reflect variation associated with lateral branching but not variation associated with extension growth (Halpern et al. 1996). Height did in fact add more precision to shrub biomass estimates in some previous studies (Murray and Jacobson 1982; Halpern et al. 1996). Nadezhdina et al. (2004) suggested that height was linearly related to stem basal diameter and biomass of plant organs. These results also agree with those of Paton et al. (2002), who confirmed that one of the best variables for quantifying biomass was $C V$. Regression equations with multiple variables were less sensitive to variations in plant form associated with site age (Alaback 1986; Halpern et al. 1996). The reduced major axis (RMS) regression method (Sokal and Rohlf 1995) was used to analyze the relationship between shrub organ/total biomass and $C V$ (Table 4), it assumes that the errors in the measurements are evenly partitioned between the $y$ variable (organ/total biomass) and the $x$ variable $(C V)$. The $R^{2}$ value of the model with RMS was slightly less than the $R^{2}$ of the model with standard ordinary least squares (OLS) regression. This revealed that $C V$ could be used alone in estimation of organ and total biomass for these four species.

\section{Conclusions}

This study suggests that it is possible to estimate plant biomass for these four shrub species. The method used in 
Table 4 Comparison of biomass models with $C V$ for shrubs between reduced major axis (RMS) regression and standard ordinary least squares (OLS) regression

\begin{tabular}{|c|c|c|c|c|c|c|}
\hline Species & Organ & Equation & Method & $a$ & $b$ & $R^{2}$ \\
\hline \multirow[t]{8}{*}{ L. chinense } & \multirow[t]{2}{*}{ Branch } & \multirow[t]{2}{*}{$\ln y=a+\ln C V$} & RMS & 2.8085 & 0.8168 & 0.890 \\
\hline & & & OLS & 4.3427 & 0.8075 & 0.893 \\
\hline & \multirow[t]{2}{*}{ Leaves } & \multirow[t]{2}{*}{$\ln y=a+\ln C V$} & RMS & 4.6152 & 0.8547 & 0.876 \\
\hline & & & OLS & 2.6147 & 0.7716 & 0.893 \\
\hline & \multirow[t]{2}{*}{ Root } & \multirow[t]{2}{*}{$\ln y=a+\ln C V$} & RMS & 4.3293 & 0.6434 & 0.510 \\
\hline & & & OLS & 3.8812 & 0.4860 & 0.571 \\
\hline & \multirow[t]{2}{*}{ Total } & \multirow[t]{2}{*}{$\ln y=\mathrm{a}+\ln C V$} & RMS & 5.1509 & 0.7087 & 0.801 \\
\hline & & & OLS & 5.0366 & 0.6415 & 0.819 \\
\hline \multirow[t]{8}{*}{ Q. fabri } & \multirow[t]{2}{*}{ Branch } & \multirow[t]{2}{*}{$\ln y=a+\ln C V$} & RMS & 1.7371 & 0.7137 & 0.903 \\
\hline & & & OLS & 4.7531 & 0.7582 & 0.920 \\
\hline & \multirow[t]{2}{*}{ Leaves } & \multirow[t]{2}{*}{$\ln y=a+\ln C V$} & RMS & 3.5094 & 0.6228 & 0.763 \\
\hline & & & OLS & 3.0673 & 0.8108 & 0.794 \\
\hline & \multirow[t]{2}{*}{ Root } & \multirow[t]{2}{*}{$\ln y=a+\ln C V$} & RMS & 4.4588 & 0.7474 & 0.648 \\
\hline & & & OLS & 5.7494 & 0.7868 & 0.675 \\
\hline & \multirow[t]{2}{*}{ Total } & \multirow[t]{2}{*}{$\ln y=a+\ln C V$} & RMS & 4.9649 & 0.6787 & 0.801 \\
\hline & & & OLS & 6.2351 & 0.7744 & 0.802 \\
\hline \multirow[t]{8}{*}{ V. negundo var. cannabifolai } & \multirow[t]{2}{*}{ Branch } & \multirow[t]{2}{*}{$\ln y=\mathrm{a}+\ln C V$} & RMS & 1.7530 & 0.7051 & 0.752 \\
\hline & & & OLS & 3.6270 & 0.5693 & 0.774 \\
\hline & \multirow[t]{2}{*}{ Leaves } & \multirow[t]{2}{*}{$\ln y=\mathrm{a}+\ln C V$} & RMS & 3.8440 & 0.6469 & 0.758 \\
\hline & & & OLS & 1.5110 & 0.6186 & 0.768 \\
\hline & \multirow[t]{2}{*}{ Root } & \multirow[t]{2}{*}{$\ln y=a+\ln C V$} & RMS & 4.1158 & 0.7533 & 0.540 \\
\hline & & & OLS & 3.6345 & 0.5810 & 0.593 \\
\hline & \multirow[t]{2}{*}{ Total } & \multirow[t]{2}{*}{$\ln y=\mathrm{a}+\ln C V$} & RMS & 4.7603 & 0.6891 & 0.742 \\
\hline & & & OLS & 4.5146 & 0.6012 & 0.759 \\
\hline \multirow[t]{8}{*}{ G. jasminoides } & \multirow[t]{2}{*}{ Branch } & $\ln y=\mathrm{a}+\ln C V$ & RMS & 4.3051 & 0.8768 & 0.936 \\
\hline & & & OLS & 4.2204 & 0.8490 & 0.937 \\
\hline & Leaves & $\ln y=\mathrm{a}+\ln C V$ & RMS & 2.6020 & 0.6335 & 0.472 \\
\hline & & & OLS & 2.0943 & 0.4664 & 0.542 \\
\hline & Root & $\ln y=\mathrm{a}+\ln C V$ & RMS & 3.0018 & 0.6935 & 0.865 \\
\hline & & & OLS & 2.8600 & 0.6469 & 0.864 \\
\hline & Total & $\ln y=\mathrm{a}+\ln C V$ & RMS & 4.6561 & 0.7592 & 0.933 \\
\hline & & & OLS & 4.5799 & 0.7342 & 0.935 \\
\hline
\end{tabular}

$C V$ canopy projected volume $\left[C V=C A \times H\right.$, where $C A$ is canopy area $\left(C A=\pi C^{2} / 4\right), H$ is height, and $C$ is crown width]

this study revealed the close relationships between total or organ biomass and $D, H$, and $C A$ and their combinations. These relationships allowed us to use simple and quick procedures to estimate total or component biomass of shrub species in subtropical China.

In this study, the power model and quadratic model were the most appropriate equations for providing a common statistical basis for describing size-biomass relationships. $C A$ as the sole independent variable gives the best fit for leaf biomass estimation. $D^{2} H$ is ideal for branch and root biomass estimation except for branch biomass of $V$. negundo var. cannabifolia and root biomass of $L$. chinense. For total biomass, $D^{2}$ is the best variable for the estimation of
L. chinense and G. jasminoides, and $D^{2} H$ is the best variable for the estimation of $Q$. fabri and $V$. negundo var. cannabifolia. Although $D^{2}, D^{2} H$, and $H$ are preferable variables for biomass estimation, $C V$ can be used alone to predict branch, leaf, root, and total biomass of shrub species with an acceptable level of accuracy and precision in investigation of the productivity of forest communities.

Acknowledgments This study was sponsored by the Funding of International Cooperative Projects no. 2006DFB91920, Chinese Ministry of Science and Technology, the Funding of Chinese Ecological Research Network, Chinese Academy of Sciences, and the National Key Basic Research Special Foundation of China (no. 2002CB4125). We would like to thank the staff of QYZ station for 
their assistance during the investigation. Thanks go to Hai-Qing Zhang, Xuan-Ran Li, Zhe Cai, and Zhen-Ying Zeng who assisted with harvesting and data processing. Their cooperation is gratefully acknowledged.

\section{References}

Alaback PB (1986) Biomass regression equations for understory plants in coastal Alaska: effects of species and sampling design on estimates. Northwest Sci 60:90-103

Araújo TM, Higuchi N, Carvalho JA Jr (1999) Comparison of formulae for biomass content determination in a tropical rain forest site in the state of Pará, Brazil. For Ecol Manag 117:43-52

Brown JK (1976) Estimation shrub biomass from basal stem diameters. Can J For Res 6:154-158

Brown S (1997) Estimating biomass and biomass change of tropical forests: a primer. FAO forestry paper 134. Food and Agriculture Organization of the United Nations, Rome

Buech RR, Rugg DJ (1989) Biomass relations of shrub components and their generality. For Ecol Manag 26:257-264

Clough BF, Scott K (1989) Allometric relationships for estimating above-ground biomass in six mangrove species. For Ecol Manag 27:117-127

Foroughbakhch R, Reyes G, Alvarado-Vázquez MA, HernándezPiñero J, Rocha-Estrada A (2005) Use of quantitative methods to determine leaf biomass on 15 woody shrub species in northeastern Mexico. For Ecol Manag 216:359-366

Frandsen WH (1983) Modelling big sagebrush as a fuel. J Range Manag 36:596-600

Haase R, Haase P (1995) Above-ground biomass estimates for invasive trees and shrubs in the Pantanal of Mato Grosso, Brazil. For Ecol Manag 73:29-35

Halpern CB, Miller EA, Geyer MA (1996) Equations for predicting aboveground biomass of plant species in early successional forests of the western Cascade Range, Oregon. Northwest Sci 70:306-320

Houghton RA (1991) Tropical deforestation and carbon dioxide. Clim Change 19:99-118

Lu JS, Lai L (2003) Biostatistics (in chinese). Higher Education Press, Beijing, pp 218

Marland G, Schlamadinger B, Leiby P (1997) Forest/biomass based mitigation strategies: does the timing of carbon reduction matter? Crit Rev Environ Sci Tech 27:213-216

Martin WL, Sharik TL, Oderwald RG, Smith DW (1981) Equations for estimating above ground phytomass in the understory of Appalachian oak forests. School of Forestry and Wildlife Resources. Virginia Polytechnic Institute and State University, Blacksburg, VA, USA

Montès N, Gauquelin T, Badri W, Bertaudière V, Zaoui EH (2000) A non-destructive method for estimating above-ground forest biomass in threatened woodlands. For Ecol Manag 130:37-46

Murray RB, Jacobson MQ (1982) An evaluation of dimension analysis for predicting shrub biomass. J Range Manag 35:451454
Nadezhdina N, Tatarinov F, Ceulemans R (2004) Leaf area and biomass of Rhododendron understory in a stand of Scots pine. For Ecol Manag 187:235-246

Návar J, Nájera J, Jurado E (2002) Biomass estimation equation in the Tamaulipan thornscrub of north-eastern Mexico. J Arid Environ 52:167-179

Návar J, Méndez E, Nájera A, Graciano J, Dale V, Parresol B (2004) Biomass equations for shrub species of Tamaulipan thornscrub of North-eastern Mexico. J Arid Environ 59:657-674

Ohmann LF, Grigal DF, Rogers LL (1981) Estimating plant biomass for undergrowth species of northeastern Minnesota forest communities. General Technical Report NC-61. USDA Forest Service, North Central Forest Experimental Station, St. Paul, MN, USA, $10 \mathrm{pp}$

Paton D, Azocar P, Tovar J (1998) Growth and productivity in forage biomass in relation to the age assessed by dendrochronology in the evergreen shrub Cistus ladanifer (L.) using different regression models. J Arid Environ 38:221-235

Paton D, Nuñez J, Bao D, Muñoz A (2002) Forage biomass of 22 shrub species from Monfragüe Natural Park (SW Spain) assessed by $\log -\log$ regression models. J Arid Environ 52:223-231

Peek JM (1970) Relation of canopy area and volume to production of three woody species. Ecology 51:1098-1101

Sah JP, Ross MS, Koptur S, Snyder JR (2004) Estimating aboveground biomass of broadleaved woody plants in the understory of Florida Keys pine forests. For Ecol Manag 203:319-329

Satoo T, Madgewick HAI (1982) Forest biomass. Junk, The Hague, Boston, $152 \mathrm{pp}$

Schimel D, Mellillo J, Tian HK, McGuire AD, Kicklighter D, Kittel T, Rosenbloom N, Running S, Thornton P, Ojima D, Parton W, Kelly R, Sykes M, Neilson R, Rizzo B (2000) Contribution of increasing $\mathrm{CO}_{2}$ and climate to carbon storage by ecosystems in the United States. Science 287:2004-2006

Smith WB, Brand GJ (1983) Allometric biomass equations for 96 species of herb, shrubs and small trees. Research Note NC-299. USDA Forest Service, North Central Forest Experimental Station, St. Paul, MN, USA

Sokal RR, Rohlf FJ (1995) Biometry: the principles and practice of statistics in biological research, 3rd edn. Freeman WH, New York, $887 \mathrm{pp}$

Tietema T (1993) Biomass determination of fuelwood trees and bushes of Botswana, southern Africa. For Ecol Manag 60:257269

VEMAP Members (1995) Vegetation/ecosystem modeling and analysis project: comparing biogeography and biogeochemistry modes in a continental-scale study of terrestrial ecosystem responses to climate change and $\mathrm{CO}_{2}$ doubling. Glob Biogeochem Cycles 9:407-437

Vora RS (1988) Prediction biomass of five shrub species in Northeastern California. J Range Manag 41:83-85

Williams RA, McCleanahen JR (1984) Biomass prediction equations for seedlings, sprouts, and saplings of ten central hardwood species. For Sci 30:523-527 